\title{
Seeking Justice and Redress for Victim-Survivors of Image-Based Sexual Abuse
}

\author{
Erika Rackley ${ }^{1} \cdot$ Clare McGlynn $^{2} \cdot$ Kelly Johnson ${ }^{2} \cdot$ Nicola Henry $^{3}$. \\ Nicola Gavey ${ }^{4}$. Asher Flynn ${ }^{5}$. Anastasia Powell ${ }^{3}$
}

Accepted: 16 April 2021 / Published online: 27 May 2021

(c) The Author(s) 2021

\begin{abstract}
Despite apparent political concern and action—often fuelled by high-profile cases and campaigns-legislative and institutional responses to image-based sexual abuse in the UK have been ad hoc, piecemeal and inconsistent. In practice, victim-survivors are being consistently failed: by the law, by the police and criminal justice system, by traditional and social media, website operators, and by their employers, universities and schools. Drawing on data from the first multi-jurisdictional study of the nature and harms of, and legal/policy responses to, image-based sexual abuse, this article argues for a new joined-up approach that supports victim-survivors of image-based sexual abuse to 'reclaim control'. It argues for a comprehensive, multi-layered, multiinstitutional and multi-agency response, led by a government- and industry-funded online or e-safety organisation, which not only recognises the diversity of victim-survivor experiences and the intersection of image-based sexual abuse with other forms of sexual and gender-based violence and discrimination, but which also enables victim-survivors to reclaim control within and beyond the criminal justice system.
\end{abstract}

Keywords Image-based sexual abuse $\cdot$ Intimate image $\cdot$ Justice $\cdot$ Law reform $\cdot$ Nonconsensual porn $\cdot$ Social rupture

\section{Introduction}

Image-based sexual abuse is a pernicious form of abuse. ${ }^{1}$ Its impacts are sometimes life-ending, often devastating, relentless and isolating. For some, it dramatically alters every aspect of their lives, causing a 'social rupture'-a schism between life

\footnotetext{
1 We use the term 'image-based sexual abuse' to include the non-consensual creating and/or sharing of nude or sexual images (or videos), including threats to share images and altered images (McGlynn and Rackley 2017; Powell and Henry 2017; Henry et al. 2019a, b; Henry et al. 2021).
}

Erika Rackley

e.rackley@kent.ac.uk

Extended author information available on the last page of the article 
'before' and 'after' the abuse (McGlynn et al. 2020). Accordingly, across the world, courts and legislatures have been grappling with how best to prevent it from happening, and how to restrict and respond to its harms (Haynes 2018; Nigam 2018; Flynn and Henry 2019). In the UK, despite apparent political concern and action-often fuelled by high-profile cases and campaigns-legislative and institutional responses have largely been ad hoc, piecemeal and inconsistent. In practice, victim-survivors of image-based sexual abuse are being consistently failed: by the law, by the police and criminal justice system, by traditional and social media, website operators, and by their employers, universities and schools (McGlynn et al. 2019).

The time is ripe, therefore, for significant change. This article seeks to provide evidence-based recommendations for reform, drawing on the most comprehensive study to date of law and policy measures relating to image-based sexual abuse, including interviews with victim-survivors and stakeholders in the UK, Australia and New Zealand. Indeed, while the immediate policy and legal focus of this article is the UK, we rely on data from across our multi-jurisdictional data set, and it is likely that our arguments and recommendations have application more broadly. We begin by outlining our methodology and participants, and locating our project within current academic literature. We then go on to explore the operation and effectiveness of current legal and policy responses. We argue that despite public and political rhetoric, as yet, policy, practice and law fail to offer an effective counter to the significant harms of image-based sexual abuse as articulated by those with whom we spoke. Law reform-while essential—is not enough. Rather, we need a new joined-up approach that supports victim-survivors of image-based sexual abuse to 'reclaim control'. Accordingly, we make the case for a comprehensive multi-layered, multi-institutional and multi-agency response, led by a government- and industry-funded online or e-safety organisation, which not only recognises the diversity of victim-survivor experiences and the intersection of image-based sexual abuse with other forms of sexual and gender-based violence and discrimination, but which also enables victim-survivors to reclaim control within and beyond the criminal justice system.

\section{Researching Image-Based Sexual Abuse}

This article draws from a three-year, cross-jurisdictional project examining the pervasiveness, nature and impacts of image-based sexual abuse by means of quantitative surveys and qualitative interviews in the UK, Australia and New Zealand. ${ }^{2}$ It is the largest study of image-based sexual abuse to be conducted to date, and this article examines the qualitative data gathered. ${ }^{3}$ Across the project as a whole, we

\footnotetext{
2 This project, 'Revenge Pornography: the implications for law reform', was funded by the Australian Research Council (DP170101433) (CI Nicola Henry, RMIT University). For further details on our methodologies, see Henry et al. (2021). The project had ethics approval from RMIT, which was ratified by Durham University, the University of Kent, Monash University and the University of Auckland.

${ }^{3}$ For a discussion of the survey data, see Henry et al. (2021).
} 
interviewed 75 victim-survivors: 25 in each jurisdiction, and 43 stakeholders across New Zealand and the UK. Victim-survivor participants were recruited via opt-in, opportunity sampling through a combination of notices via local charities, universities, relevant social media groups, word of mouth and through paid Facebook advertisements. The interviews were conducted either face-to-face, via telephone or a Voice over Internet Protocol (VoIP) service, and typically lasted around an hour. The interview questions were semi-structured in order to facilitate consistency across the project and between interviewers, and to allow for focus on particular areas of interest and concern. Victim-survivor participants were reimbursed in retail vouchers for their time and travel. ${ }^{4}$ With permission, the interviews were recorded and transcribed, with participants given pseudonyms by the researchers.

Stakeholder participants were recruited through snowball sampling within professional networks, as well as targeted approaches, in order to address potential gaps in our victim-survivor interview data. Accordingly, we spoke to representatives from organisations across the UK and New Zealand who work with survivors of sexual abuse and/or image-based sexual abuse, with black and minoritised women and with children, as well as charities focused on internet safety, police officers, lawyers, legal advice and support workers, and policymakers. ${ }^{5}$ The interviews were conducted either face-to-face or via telephone or a VoIP service and typically lasted around an hour. As with the victim-survivor interviews, the questions were semi-structured and the interviews were recorded and later transcribed. For all interviews, appropriate consent was obtained, as well as agreement to individual and institutional anonymity. ${ }^{6}$

Once data collection was complete, the de-identified victim-survivor and stakeholder data were exported into NVivo, a qualitative data analysis software programme. The data were coded across the research team through an iterative process in order to identify, analyse and report on patterns or themes. In so doing, our analysis is grounded in the insights of feminist standpoint epistemology and methodology, which views victim-survivors as having expert knowledge of image-based sexual abuse, and which is fundamental and central to our analysis (Harding 2004; McGlynn et al. 2020).

\footnotetext{
${ }^{4}$ UK participants received vouchers to the value of $£ 40$, Australian participants, \$50AUD, and New Zealand participants, \$50NZD.

5 We identify our stakeholders according to three broad categories: police and criminal justice personnel, lawyers and those working with victim-survivors. We conducted 35 interviews with a total of 43 stakeholders (some interviews involved more than one staff member): five with police and criminal justice personnel, 10 with lawyers from law firms or legal services and 20 with individuals working in victim support services. Ten stakeholder interviews were conducted in New Zealand with 10 participants, seven interviews were conducted in England and Wales and Northen Ireland with 23 participants, and eight interviews were conducted in Scotland with 10 participants. No interviews were conducted with Australian stakeholders, as members of the team had already conducted extensive stakeholder interviews in Australia in an earlier project. See e.g. Henry et al. (2018a; 2019a, b).

${ }^{6}$ We recognise that institutional anonymity prevents us from publicly acknowledging the support of charities, organisations and individuals that might benefit from being named as participants in this project, e.g. through increased recognition or funding. However, for a number of our participants, it was important that they were able to speak freely and without association.
} 
Of our 75 victim-survivor participants, the vast majority identified as women $(89.3 \%, n=67)$, compared with men $(8 \%, n=6)$, trans $(1.3 \%, n=1)$ and self-identified 'other' $(1.3 \%, n=1)$. This was reflected in our UK sample of victim-survivors $(n=25)$ of which 22 identified as women, with three identifying as men. Overall, our participants also predominately identified as heterosexual/straight $(62.7 \%, n=47)$, followed by bisexual $(18.7 \%, n=14)$, lesbian $(2.7 \%, n=2)$, gay $(2.7 \%, n=2)$, queer $(2.7 \%, n=2)$, 'other' $(8 \%, n=6)$ and 'unsure' $(2.7 \%, n=2)$. Of the $25 \mathrm{UK}$ victimsurvivors, one identified as gay (4\%), one as lesbian (4) and four as bisexual (16\%). In terms of race and ethnicity, $81.3 \%(n=61)$ identified as either White, European or Pākehā, while the remaining respondents selected either indigenous or Black, Asian and Minority Ethnic (BAME) backgrounds, including New Zealand Māori (2.7\%, $n=2)$ and Black British $(1.3 \%, n=1)$. Three of the UK victim-survivor participants identified as BAME (12\%). Twenty-four percent $(n=18)$ of our participants overall identified as living with a disability, including six based in the UK (12\% of UK victim-survivors). Unsurprisingly, and in line with other projects, the majority of participants in the study overall were younger adults ${ }^{7}: 68 \%(n=51)$ aged $18-29$ years, followed by $20 \%(n=15)$ aged 30-39 years, and 12\% $(n=9)$ aged over 40 years. Of the UK participants, 18 (72\%) were aged 18-29 years, four (15.3\%) were aged 30-39 and three were aged over 40 (12\%).

Despite the size of the study, we were not able to recruit evenly across demographic categories when compared to broader population demographics, including ethnicity, age, sexuality, gender and disability. This meant that we were unable to investigate in depth the ways in which different vectors of marginalisation might intersect with image-based sexual abuse-insofar as this would have been possible to do robustly with a sample of 25 . Therefore, while our analysis offers some insights into the intersectional harms of image-based sexual abuse, these are necessarily limited. The narrative accounts included in this article do not speak comprehensively to marginalised peoples' experiences, or to the range of intersectional contexts in which image-based sexual abuse victimisation can occur. They cannot and do not fully represent the experiences of black and minoritised individuals for whom the harms of, and responses to, image-based sexual abuse are racialised, nor do they speak to the full spectrum of experiences of LGBTQI+ victim-survivors or of those with a disability (see further Thiara and Roy 2020). Similarly, though a number of the victim-survivors spoke about abuse that had happened while they were at school, we were unable to draw specific conclusions relating to the impacts of image-based sexual abuse on children and teenagers (see further Childnet International 2019). Further work is urgently needed to address the experiences of individuals and groups facing interlocking forms of oppressions in society, inclusive of racism, xenophobia, ableism, transphobia, heterosexism and ageism (see Henry et al. 2021; Dodge 2020).

\footnotetext{
7 Individuals were required to be 18 years of age or older to participate in this study.
} 


\section{Experiencing Image-Based Sexual Abuse}

The victim-survivors we interviewed across the UK, Australia and New Zealand reported a diverse range of experiences of image-based sexual abuse, and in this section we draw on the experience across all three jurisdictions. A significant majority reported having had nude or sexual images of them distributed without their consent. This included those who had initially shared the images consensually and those who were unaware they were being filmed or photographed at the time. Many participants described how images of them were shown to groups of friends or colleagues via mobile phones or mobile apps, or posted on pornographic websites, social media sites, chat rooms or imageboard sites. More than a third of UK participants, for example, also experienced someone explicitly threatening to share nude or sexual images of them, sometimes with the purpose of control and/or coercion into an unwanted act, such as paying money (blackmail), sending more images, or controlling the victim-survivor within the context of an ongoing or former intimate relationship. The significance of threats is further emphasised by the findings of our multi-jurisdictional quantitative study, where one in five $(18.7 \%)$ respondents reported experiencing threats, with more than half of participants identifying as victim-survivors of image-based sexual abuse reporting threats (Henry et al. 2021, 11, 30). These results are striking, particularly because the use of threats is less recognised and not always criminalised in many jurisdictions internationally, unless prosecuted under extortion or blackmail laws.

A majority of participants (across all jurisdictions, including the UK) also reported that someone had created or taken nude or sexual images of them without their consent. In some cases, participants were filmed or photographed without their knowledge when they were changing, showering, asleep, or drug- or alcohol-affected, or with the aid of a hidden camera. For a very small number of participants, images of them were digitally altered to make it look as if they were posing or performing in a nude or sexual photograph or video (for example, through image editing software). Others described being pressured or coerced into either having photos or videos taken of them, for example being groomed or coerced into sharing sexual images when they were children by predators online, or by intimate partners as adults. Additionally, these abuses were not limited by location: victim-survivors spoke of having images taken or shared at home, work, school and parties, as well as more widely online and offline. It was common for participants to identify that intimate photographs or videos of them had been spread 'virally' among their social networks.

The overwhelming majority of perpetrators that participants identified were men. Most of the reported abuse had taken place within the past five years, but, for some, the experiences had taken place a decade or so ago, with the effects continuing to impact on their lives.

Significantly, more than half of the UK victim-survivors had experienced multiple forms of image-based sexual abuse, by the same perpetrator or by multiple perpetrators. These findings closely parallel those from the wider 
multi-jurisdictional qualitative study where overall two thirds of victim-survivors interviewed experienced more than one form of image-based sexual abuse. Indeed, across all participants, we found that the most frequent form of imagebased sexual abuse was images being taken without consent, followed by images shared without consent, and threats being made to share images. These qualitative findings further resonate with evidence from our survey of over 6000 participants across the UK, New Zealand and Australia, where $37 \%$ of respondents had experienced at least one form of image-based sexual abuse (Henry et al. 2021, 11). It is likely, however, that these proportions are underestimates, because victim-survivors did not always know for certain whether images of them had been shared or taken. In addition, for many, the image-based sexual abuse occurred in conjunction with, or alongside, multiple experiences of other forms of sexual violence, domestic violence, stalking and sexual harassment-both online and offline. Across all participants, including the UK data set, approximately one third of the image-based sexual abuse occurred in the context of a broader pattern of intimate partner violence and abuse.

\section{Harms of Image-Based Sexual Abuse: Constancy, Isolation and 'Social Rupture'}

What was also clear from our interviews with victim-survivors across all three countries is that image-based sexual abuse for many can be a devastating form of abuse, engendering serious, multifaceted and enduring harm (see further Bates 2017; McGlynn et al. 2019, 2020). A significant number of participants in our study spoke of their experiences in terms of an extreme, unsettling and intrusive violation: a form of 'social rupture' where they experienced the abuse as "life-ruining," "hell on earth," a "nightmare ... [that] destroyed everything." It is, in the words of Anna, "torture for the soul". ${ }^{8}$ Additionally, many participants did not speak of the abuse in terms of a discrete incident which happens and then comes to pass, but rather in terms of the "constancy' of the harms: their "permanence," "ongoingness" and "endlessness". The abuse is often ongoing, cumulative and relentless because the photographs or videos remain 'out there', constantly available to be shared online, viewed and rediscovered, with each new viewing or distribution a form of abuse. Accordingly, many victim-survivors experienced a profound sense of 'isolation', shattering connections with family and friends, from the online world and social media, as well as from society as a whole. Many of those we spoke to had withdrawn from social media, notwithstanding the significant adverse impacts on their social and professional lives, cutting them off from friends, family, peers and other forms of civic engagement.

\footnotetext{
8 Throughout this article, we use a variety of quotes from our interviews with victim-survivors. While we provide the pseudonym of participants for longer quotes, we have chosen not to do this for shorter quotations. This is because many of the words were used by multiple participants, and even more participants conveyed experiences which resonated with these terms, even if they did not use the identical word. We decided to adopt this approach to avoid creating a hierarchy between participants and/or quotes (on the basis of frequency used) in the depiction of short phrases.
} 
In short, image-based sexual abuse can effect all-encompassing social harms, frequently generating such significant impacts due to the lived reality for many of inequality and discrimination, with misogyny and sexual double standards, for example, shaping the impacts of abuse. The often devastating, constant and far-reaching harms of image-based sexual abuse underscore the importance of responding comprehensively and holistically to this pernicious form of abuse. To emphasise: we found that victim-survivors described their harms in more holistic and nuanced ways than commonly suggested in law and policy approaches to this issue. Thus, they experienced harms explained as, for example, social rupture, isolation and constancy, rather than separating their lives into categories such as psychological, physical and/or financial harms (see also McGlynn et al. 2020).

\section{Intersectional, Racialised and Gendered Harms}

Our intention in emphasising the commonality of 'social harms' experienced by many victim-survivors is not to suggest there is a single way of understanding or experiencing these harms or image-based sexual abuse more broadly. Nor, in seeking to emphasise and gain recognition for particular understandings of harm, are we wishing to place more importance on some experiences over others (McGlynn et al. 2020; McGlynn and Johnson 2021) — not least because this can risk new ways of "othering, stigmatizing, violating" those who have experienced sexual violence (Gavey and Schmidt 2011, 452). The harms of image-based sexual abuse are experiential, contingent and intersectional. Individuals are differentially exposed to image-based sexual abuse, and the risk of victimisation is distributed unequally across demographic patterns and vectors of marginalisation, including gender, age, sexuality, indigeneity, race and ethnicity. And while women, LGBTQI+ people and those from minority racial and ethnic communities are more significantly affected by image-based sexual abuse and experience greater adverse impacts (Henry et al. 2021,177 ), there is no essential experience within or across these groups. Accordingly, any account of the experience and harms of image-based sexual abuse therefore needs to engage both with the dominant conceptual paradigms of sexual violence as predominantly reflective of systems of gender inequality, and with the multiple, interlocking structural inequalities that produce multiple relations of power and abuse (Crenshaw 1991; Hill Collins and Billge 2016).

While a number of studies have found similar rates of image-based sexual abuse victimisation for both women and men (Powell et al. 2018; Henry et al. 2021), it is clear that the impacts and perpetration of image-based sexual abuse are experienced differently according to gender. Many of the women victim-survivors who shared their stories with us have experienced significant, often all-encompassing harms-in large part because of the social stigma and shame around women's sexuality. To understand image-based sexual abuse is then to recognise that we continue to live in deeply gendered societies which are characterised by misogyny, male entitlement and sexual double standards. Compare, for example, a comment from one of our UK participants, Vicky, when asked why she thought her boyfriend had shared intimate 
images of her, with her description of her experience when reporting that abuse to the police:

[Why did he do it?] It's this whole thing of "how many girls have you slept with?" "I've slept with this many." It's all this lad point, laddish lifestyle ... I felt like [the police] just did think "oh, it's just a girl sending nudes out, what does she expect?" And I don't know, it didn't have a good feeling to it at all ... It was almost like “....well, you should've been more careful. Why did you let him have this picture?" And obviously all that is important, but I did definitely feel like I was back in school and sat down by a teacher and getting told off or something.

A number of the victim-survivors we spoke to reflected on how their particular socio-political positions and identities intersected with gender and inflected the harms, oppressions and consequences they encountered-emphasising the importance of an intersectional and situated understanding of image-based sexual abuse. For example, UK participants reflected on how their age and life stage at the time of experiencing the abuse intersected with the shame they experienced. This was the case for Mary, for example, who is the mother of a teenage son:

I felt like I was too old for [the image-based sexual abuse] to happen! Especially when I look at the conversations and the group chats my son's having at 13, and I think, gosh ... How could [my intimate pictures] have been put in a group chat at [my] age? I feel like it's something that happens to teenagers/ early 20s. I think probably my age carries part of the shame. It does; the fact that I feel like I'm way too old to be in that situation.

Additionally, Zoe was sexually abused at the age of 13 by an older teenage male who also took, shared, and threatened to share, her sexual images as part of the abuse. Below, Zoe reflects on how her age at the time of the abuse compounded her feelings of shame, which in turn impacted her ability to report the abuse and receive support:

At the time I didn't know that him taking a picture was illegal, I just knew that having sex was illegal ... because I knew that I was under the age [of consent] and he was over the age. And I was worried that I was going to get in trouble for that ... I told my mum ... she was quite disgusted by ... me saying I'd had sex ... I really played [the abuse] down, which meant that I couldn't then ask my mum to go to the school to support, to stop people from ridiculing me about it. Because when you're a teenager you think the worst thing to do when you're being bullied is to report it because it will make it worse.

Even though the sexual abuse took place more than a decade ago, Zoe described how she still continues to experience a lingering sense of shame, which she connects to her then young age: 
It's something I feel a lot of shame for it now ... it's not something that I tell to anybody. So it's not a story I took with me to university or that I took to, you know, into my life now. And it's not something that I would ever converse with my mum about anymore, it's just something that happened and I would never bring that up to anybody because I feel a lot of shame for it. Not just the photo but for being sexually active at such a young age.

Many survivors also reflected on the ways in which the image-based sexual abuse had profound impacts on their mental and physical health, and a range of stressrelated conditions such as chronic pain, headaches, spasms and nausea. However, the health impacts of image-based sexual abuse were particularly pronounced for victim-survivors living with disabilities. Vicky, for example, recounted how she was greatly upset after she discovered her boyfriend had shared intimate images of her, which in turn destabilised her epilepsy and required emergency medical care:

So obviously he didn't cause the seizures but I feel like if I hadn't been so upset ... stress can trigger seizures and ... I wasn't looking after myself, you know, I hadn't been eating, and sometimes when my blood sugars drop that can trigger a seizure as well ... so I was just so weak, I was highly distraught, I'd had no sleep because I'd literally been crying, I was so upset all night, I hadn't really ate anything and I just think my body, obviously with being epileptic as well, it just completely gave out... I had something like over 30 seizures ... I was in hospital for a while ... they say I could've died.

Further, Fiona described how her partner taking a series of intimate images of her without her consent compounded her pre-existing mental health conditions, which has impacted her ability to work:

My whole mental health has been a bit crap like pretty much all my life. But at that point ... I was working part-time ... But I sort of I don't know, I just stopped ... my anxiety got [a] lot worse ... I haven't worked since then ... People think it's because you've got mental health problems ... Like no actually, you're not understanding [the abuse] has made my mental health problems worse, like my whole situation.

Although some UK interview participants identified as BAME and/or LGBTQI+, our data did not clearly speak to the ways in which ethnicity and sexuality can impact experiences of, or responses to, image-based sexual abuse. However, across the international data set we are able to identify such examples. Tia for instance, a participant from New Zealand, reflected that not only was her experience of abuse deeply violating, but it also potentially jeopardised her safety by putting her at increased risk of so-called honour-based violence. Additionally, one of our Australian participants, Maya, told us how the harassment and 
victim-blaming she experienced after someone created digitally altered images of her, and then circulated them online, were imbued with racism and misogyny:

I got a lot of hate and a lot of it was because I'm brown-skinned, I'm a woman of colour, I'm not conventionally attractive in that I'm not skinny and I'm not white. The hate was not only sexist and sexualised but it was also racialised as well. I had racialised hate and misogynistic hate, and the commentary was, "You're ugly and gross, why would this happen to you?" or "You should be flattered," or "You're asking for it, you're a slut, you're a whore, what do you expect?"

In relation to sexuality, another Australian participant, Kyle, who identifies as pansexual, reflected on how his experience of having sexual images shared online without his consent was imbued with homophobic abuse, with the abuser calling him a "slut" and falsely claiming he had HIV and had "gone around infecting people."

Taking account of these varied experiences, there can be little doubt that privilege and power (and the lack thereof) shapes the nature, experience and harms of image-based sexual abuse. It is vital, therefore, that in seeking justice and redress for victim-survivors, law, policy and practice recognise and remedy this.

\section{Redressing the Justice Gap: Toward a Comprehensive Criminal Law in the UK}

Victim-survivors and stakeholders were clear that the current UK criminal law is consistently failing those who experience image-based sexual abuse. The law is confusing, inconsistent, unduly complex, out of date and difficult to prosecute, and contains many significant loopholes (Rackley and McGlynn 2018; Dymock and van der Westhuizen 2019; McGlynn et al. 2019). In the following sections, we narrow our focus to concentrate on the accounts of the UK victim-survivor and stakeholder participants in order to examine several different strands through which image-based sexual abuse is, and might be, responded to in the UK. In terms of law reform, our specific focus is on the law in England and Wales, with Scots law currently providing a far higher level of protection from these abuses (Chalmers and Leverick 2017). We do so not because experiences of, and responses to, image-based sexual abuse are necessarily jurisdictionally different, but rather because when exploring what is 'justice' for victim-survivors of image-based sexual abuse, the local law and criminal justice system, as well as the (un)availability of support structures, are highly relevant.

In arguing for a criminal sanction, we are not suggesting that criminalisation should be the first or only response to image-based sexual abuse, or that it is the best means to tackle such behaviours. As reflected in our multifaceted strategy outlined below, the criminal law should only ever be seen as one of many varied and multiple means of ensuring justice and redress. The criminal law does, however, 
have a role to play in providing recognition and redress to some victim-survivors of image-based sexual abuse, as well as supporting education and prevention measures; albeit within a framework that appreciates the considerable challenges of deploying the criminal law, not least its uneven application in practice (see Waldron 2010; McGlynn and Rackley 2017; McGlynn and Johnson 2021). Moreover, as McGlynn and Johnson have argued in the context of cyberflashing, engagement with the law is vital in the current political climate where criminal law reform is being actively considered:

Without change, the law will continue to ignore the harms experienced by women, it will marginalise their experiences, neglecting to recognise them or provide redress. Engaging with the law, therefore, is a complex equation: seeking to harness its transformative power, while resisting its capacity to distract, and reinforce disadvantage and oppression ... To abandon this terrain now would be to concede ground to what can be a powerful tool against harm and abuse. It would also risk new criminal laws being introduced that do not adequately or effectively provide recognition, redress or a sense of justice to victim-survivors. (McGlynn and Johnson 2021, 62)

\section{Understanding the Nature of Image-Based Sexual Abuse}

Many of our participants reported that one of the fundamental problems with the current criminal law is its failure to understand the experience and nature of imagebased sexual abuse. This misunderstanding takes two forms: first, a failure to recognise the experience as one of sexual abuse; and, second, an erroneous presumption that the perceived motivation for abuse is either malicious intent or 'revenge'.

\section{"It's an abuse of me and my body... it's sexual abuse"}

One of our stakeholders, who supports victim-survivors, described how the law fails to "capture the real essence" of image-based sexual abuse by not understanding it as a form sexual abuse. For example, many victim-survivors described to us how they experienced these harms as a form of abuse similar to sexual assault. This echoes earlier research (Henry et al. 2017; McGlynn and Rackley 2017; McGlynn et al. 2017; McGlynn 2017; North Yorkshire Police and Fire Commissioner 2018; Powell et al. 2018). Lucy, whose ex-boyfriend had uploaded sexual images without her consent onto porn websites, commented: "I feel like it's on a par with sexual abuse, just the toll it's taken on me. And I know people might say that sounds like an exaggeration, but that is genuinely how I feel." This was echoed by Sonia, who said: "I just feel like it's more like sexual abuse ... like cyber sexual abuse." Deborah described it as a "digital version" of rape: "you're still being exploited, you're still being made very vulnerable and it's still against your will ... you're being raped, it's just in a different way, it's just a new version of it."

And yet, non-consensual disclosure offences are not categorised as sexual offences, leading to a number of unjustifiable and discriminatory consequences, 
the most egregious of which is the lack of automatic anonymity for complainants. This means that their names can be-and are-published in news reports and across social media and the internet. This ironically magnifies the abuse by drawing further attention to the primary abuse, thus likely increasing visibility and vulnerability for victim-survivors. This risk of further exposure through publicly naming victimsurvivors can have a significant impact on their lives and those of their friends and family. As one stakeholder who works with victim-survivors told us:

The saddening part is that they named [the victim-survivor] in the court ... her name was in the [news]papers, and then it went viral. ... She's told me that was worse than the crime. ... The fact that everybody knew who she was and what had happened to her, it was quite bad really. ... She'd got a young child as well.

Unsurprisingly then, and in line with other research (e.g. North Yorkshire Police, Fire and Crime Commissioner 2018), we found that the absence of anonymity is a key barrier to victim-survivors reporting to the police. Lucy's comment is reflective of others:

Because there is no anonymity ... [reporting to the police is] not something I would do again. Even if you could guarantee me that the police would be very sympathetic and take it seriously and investigate, I still wouldn't do it because there's no anonymity.

The lack of automatic anonymity in this context is - in the words of our interviewees-“ridiculous", "crazy," "outrageous" and "such an obvious disaster". It is not, however, the only consequence of the failure to correctly categorise image-based sexual abuse. A number of police officers expressed their frustration at their inability to take appropriate action against a perpetrator, for example by seeking to secure a sexual harm prevention order, despite the perpetrator being at high risk of future offending. Other stakeholders highlighted negative procedural consequences, including the use of special measures and the allocation of an appropriately trained judge: "whereas a sexual assault has to go before a judge ... who's had the specialist training ... I don't think [image-based sexual abuse] would" (lawyer working with victim-survivors).

\section{"It's not one act of revenge after a breakup": the multifarious motivations of image-based sexual abuse}

Our participants also considered there to be widespread misunderstandings relating to the motivations of perpetrators. In particular, the law assumes the abuse is motivated either by sexual gratification or aiming to cause harm or distress. This fails to understand the breadth of motives, and therefore provides no redress for many victim-survivors. In fact, our research reveals a complex picture in which there is rarely a single motivation for image-based sexual abuse. Participants identified a range 
of multiple, overlapping and interlocking motivations, including control, attention seeking, jealousy, obsession, misogyny and 'lad culture', sexual gratification, a "prank", distress, humiliation, entitlement, and to build up social capital. ${ }^{9}$

Over half of the victim-survivors we spoke to considered a primary motivation for the perpetrator was "control". This parallels extensive research on other forms of domestic and sexual violence which identifies power and control as being a central motivation for perpetrators (see e.g. Kelly 1988; Stark 2007). It also parallels survey findings, where over half of those self-reporting as perpetrators stated that one of their motivations was control (Henry et al. 2021; see also Powell et al. 2019). Additionally, many of our interview participants who identified control as being a key motive had experienced image-based sexual abuse within the context of an intimate relationship-emphasising the strong relationship between this form of abuse, domestic abuse and coercive control (Stark 2007). As one participant, Liz, reflected:

He just was not a nice guy. ... He was very controlling and manipulative. So, when we were going out ... he would jokingly say ... "If we ever fall out I can show people these photographs" ... And in hindsight now, I realise that that is very controlling behaviour.

Similarly, one of the stakeholders who works with victim-survivors told us: "It's not one act of revenge after a breakup. It's a continued pattern of control. ... It's another means to degrade them, to humiliate them, shame them, control them, maybe coerce them into coming back".

Although control was the dominant motivation, another key theme was 'misogyny and entitlement', where men are more motivated by how they are perceived by others, as opposed to harming the victim-survivor (McGlynn et al. 2019). Victim-survivors reported motivations relating to misogyny, sexual entitlement and 'lad culture', highlighting the gendered dimension to experiences of image-based sexual abuse. Mary, for instance, spoke of her partner seeking "more notches on his bedpost," while Alison reflected that her ex-boyfriend was "probably a bit of a show-off" in sharing her sexual images without her consent. Participants also spoke of the perpetrator's sense of entitlement. In a number of cases, the victim-survivor had sought to protect herself by refusing to take and/or send private sexual images, only to find that the perpetrator had taken images of them without her knowledge (see further McGlynn et al. 2019).

This range of motivating factors is not reflected in the current law in England and Wales, where the offence of non-consensual distribution of private sexual images requires a single identifiable intention to cause the victim-survivor distress. ${ }^{10}$ Not

\footnotetext{
${ }^{9}$ Of course no one, including victim-survivors, can really say what someone else's motivations are. Nonetheless, the motivations identified by our participants reflect the findings of other research with perpetrators (see further Hall and Hearn 2017; Mortreux et al. 2019; Powell et al. 2019; Henry et al. 2021).

${ }^{10}$ In England and Wales: Sects. 33-35 of the Criminal Justice and Courts Act 2015, extended to Northern Ireland by virtue of ss 50-53 of the Justice (Northern Ireland) Act 2016. Scots law includes reckless intention alongside distress, see Sect. 2 of the Abusive Behaviour and Sexual Harm (Scotland) Act 2016.
} 
only does this requirement only cover one type of motivation; it adds an additional threshold which is restricting the application of the law. As one police officer noted:

I don't really see why anybody would share images of an ex-partner without realising that it might cause them some distress. ... It shouldn't be included as something that we need to prove. Because all they've got to do is turn around in interview and say "oh, no, I just did it as a joke, or I never thought they'd see it." And it's very easy to get out of I think. Unless you've got something like a text or an email that says, "I'm doing this to you." ... Then yeah, it's very difficult to get anywhere with it.

This was also reflected in the experiences of victim-survivors. Only a very small number of those we spoke to had seen the perpetrator prosecuted and convicted of a crime, and none were based on legislation specifically criminalising the non-consensual dissemination of intimate images. Many of our participants were told they were unable to bring their case within the remit of the criminal law because it was not possible to demonstrate the limited intention requirements. Julia, for example, whose ex-partner used her sexual images to set up a fake profile on a porn website on which he encouraged people to "take [her] down dark alleys and rape [her]", was told by the police that there wasn't sufficient evidence to suggest he intended to cause her distress, as they believed he didn't ever want her to find out what he was doing. Rhona, whose ex-boyfriend also posted images of her on porn and social media websites, alongside comments encouraging people to make up sexual fantasies about her, was told by the police she had no case because "[the police officer] didn't think it was revenge porn because there wasn't any revenge in it" (despite, of course, this not being a legal requirement) (see also Bond and Tyrell 2018; Henry et al. 2018a).

This focus on intention is not only out of step with other sexual offences, labelled not because of the motivation of the perpetrator but because of the mode of perpetration (McGlynn 2018), but it also highlights the problem with legislation that requires one or two identifiable reasons for behaviour from a list of 'acceptable' motives. We know that there is rarely a single motivation for image-based sexual abuse (see also Ruvalcaba and Eaton 2020; Powell et al. 2019; Henry et al. 2021). This not only leaves many victim-survivors without a (criminal) legal remedy, but also encourages and legitimates the still prevalent view that (some forms of) imagebased sexual abuse are 'a laugh' or 'harmless', or the victim-survivor is in some way culpable. Our research found that victim-blaming continues to be widespread, particularly online and among the police and schools. As one stakeholder who works with victim-survivors told us:

When we promote articles or we promote posts on social media ... most of the comments will be, "Well, that's what you get for sharing images." "Well, they shouldn't have shared them in the first place." "What did they expect? ... [Or] they're just a really passive, kind of, "This won't happen to me. I'm very careful" ... passing the blame [to victims]. 
Another stakeholder described a situation where a school had asked her to come in to "terrify" pupils into not sending images:

How they decided to approach it was to call [up] individual young women who'd been victims ... literally in front of the whole school and to ... say "if you didn't take images of yourself then you wouldn't be like these girls". It was horrific.

It is little wonder that a number of the victim-survivors we spoke to had experienced victim-blaming attitudes (or, in some way, blamed themselves). As Louise, whose intimate pictures with a woman work colleague were shared without her consent, told us.

... I didn't see myself as a victim. I saw myself as a person that had, it wasn't a relationship, it was an affair ... While we were in this quite lustful affair, that was just what we did, and I just sent her pictures and that was kind of the relationship and how the relationship evolved. It was always my choice to send the pictures, so I kind of felt like you just can't turn around and go, "It's not my fault" when actually, if you hadn't have sent those pictures in the first place, she wouldn't have those pictures. Does that make sense?

Victim-blaming can have serious, life-threatening consequences. Heather, for example, told us about her experience reporting her abuse to the police:

The case officer I was given came around two days after I reported it and they took my first statement ... and they instantly like victim-blamed me for what had happened. She said "well I guess you've learnt your lesson." And I was really sad by that. Because it felt like if the police didn't have any sympathy or anything, then nobody else probably would either. So it made me feel really bad. And I had to get my friend to come over that night because I felt really unsafe in myself. I thought I'd probably harm myself.

\section{"Still a picture of you": deepfakes and developing technology}

Another failure identified by participants is the exclusion from English law of the distribution of images or videos that have been digitally altered to make them sexual. ${ }^{11}$ This can involve manipulation of photos, commonly known as 'photoshopping' and 'fakeporn', as well as the use of recently created artificial intelligence programmes to create realistic pornographic videos, often referred to as 'deepfakes' (Chesney and Citron 2019). While this technology is driving political debates about potential interference in democracy, not surprisingly, the vast majority of deepfakes

\footnotetext{
11 In England and Wales and Northern Ireland, 'altered' images are explicitly excluded by virtue of s 34(5) of the 2015 Act. Altered images are not, however, excluded from the Scots provisions - s 3(2) Abusive Behaviour and Sexual Harm (Scotland) Act 2016.
} 
created are pornographic (Ajder et al. 2019; Holmes 2019). Sarah experienced this form of abuse:

I got an email ... saying ... "Are you sure you want this on the internet?" And it was a load of very explicit porn with my name attached and my face attached. But it was photoshopped. ... He'd clearly gone through my Facebook photos ... and then photoshopped me into some very hardcore porn and had put it on the internet under my real name with my Facebook profile picture as the profile picture up there. So it was very identifiably me.

While 'photoshopping' technology has been available for decades, the use of artificial intelligence is making 'fakeporn' videos increasingly sophisticated (Henry, Flynn and Powell 2018b). It also appears to be increasingly common. In our survey of over 6000 participants across the UK, New Zealand and Australia, 14\% disclosed that someone had either created or shared digitally altered nude or sexual images of them without their consent (Henry et al. 2021). Indeed, of those whose images had been taken without their consent, in one third (34\%) of cases the images had been digitally altered (Henry et al. 2021). So far, the UK Government has refused to strengthen the law to cover 'fakeporn'. Indeed, in 2016, the Minister responsible stated that the harms experienced by the non-consensual sharing of altered images were not as great as for 'original' images (Bradley 2016). Our research would suggest that this is misguided. Advancements in artificial intelligence have made it increasingly difficult to tell the difference between the fake and real images, and so the harm and harassment experienced by victim-survivors can be just as significant (see also Flynn 2019). Sarah, for example, told us she was left feeling "extremely exposed and very much attacked, and just really, really vulnerable" after her ex-partner distributed fake pornographic photos of her. As one stakeholder, who works with victim-survivors, explained to us: "it's still a picture of you. ... It's still abuse".

\section{Excluding 'intimate' images}

For the current criminal law in the UK to bite, a non-consensually distributed image must be both 'private', that is showing "something that is not of a kind ordinarily seen in public", and 'sexual', that is exposing the victim-survivor's "uncovered genitals or pubic area," or its "content, taken as a whole, is such that a reasonable person would consider to be sexual because of its nature". ${ }^{12}$ This definition has the effect of excluding a whole range of images that might be considered 'intimate' but which are not 'sexual' and/or are of activities ordinarily seen in public and therefore not included. In particular, the exclusion of some 'intimate images' risks reinforcing dominant norms, particularly around gender, race, ethnicity, religion and sexuality.

\footnotetext{
12 Criminal Justice and Courts Act 2015, s 35. See also s 3 of the Abusive Behaviour and Sexual Harm (Scotland) Act 2016, which though using the language of intimacy, adopts much the same approach.
} 
As one stakeholder who supports black and minoritised women experiencing abuse told us:

A lot of times what would be considered as being sexually explicit or a sexual image for BME communities is very different than what would be considered sexually explicit in mainstream communities. So it could be as simple as a photograph of a girl without her headscarf when she normally wears a headscarf. It could be a picture of a girl with boys or vice versa, boys with girls.

The current approach, therefore, excludes many images which, if distributed without consent, may cause significant harm including the examples above of an image of a Muslim woman without her usually worn headscarf, or of a Hasidic Jewish woman with her legs or ankles exposed.

There are also other examples of potentially 'intimate' images that are not currently covered. The same stakeholder also suggested that current definitions similarly exclude cases involving sexuality:

It could be a young person who is in a place they shouldn't be. So like, for example, if they're transgender or if they are gay or lesbian and they are photographed in like a gay bar or something like that, that would be enough of a threat.

Therefore, a more inclusive approach, with broader definitions of the types of images covered, would be welcome to ensure that the criminal law extends to all forms of intimate images that an individual has not chosen to share publicly.

\section{The "panic that something is going to happen": the life-threatening and paralysing nature of threats}

A number of victim-survivors we spoke to had experienced threats to share nude or sexual photographs or videos of them without their consent, echoing survey findings which have found that as many as one in five respondents had experienced someone threatening to share a nude or sexual image without their consent (Henry et al. 2021, 11). While many of the threats made to our participants were subsequently carried out, this was not always the case. Threats to share images can in and of themselves have significant, life-threatening impacts. Participants described the paralysing effect it had had on their daily lives. Stephen, for example, who was threatened by a former woman friend, told us:

Before all this happened, I had no problem sleeping eight hours a day. [Now] I'll be lucky if I sleep two hours straight and don't get up and check my phone and then I go back to sleep and wake up again and check my phone.... And it's just this panic that something is going to happen. And it's like, as time goes on, it doesn't really fade. Because I think like the second that ... I'm not prepared for it, then it's going to happen. 
For others, the threat of disclosure is continuous, cumulative and can become overwhelming. As Louise told us, the fear of images being shared by a former girlfriend was such that she tried to end her life: "I was embarrassed and I was ashamed ... and I felt stupid. ... Even now I'm still not sure whether or not she will send them. ... My mental health deteriorated quite significantly. ... I took an overdose". While many of our participants who had experienced threats did so in the context of an abusive relationship, this was not always the case. Threats can be made in a wide variety of contexts and relationships.

In light of these experiences, it is deeply concerning that threats are not covered by English law (McGlynn and Rackley 2017). Unlike in Scotland, where the threat to distribute private sexual images is criminalised, ${ }^{13}$ in England and Wales and Northern Ireland there is no specific provision covering threats, with the result that there is often nothing the police or victim-survivor can do to pre-empt or stop the abuse from happening. The urgent need to criminalise threats was also recommended by a recent domestic homicide review where police were hindered in the action they could take when a victim was being threatened (Lyons 2019). As one stakeholder who works with victim-survivors commented: "they go to the police and the police say, 'Well, there's not really anything we can do. Because they're not really breaking any laws. Come back to us if it gets shared.'" Further, while threats to distribute images may be part of a broader pattern of coercive control within the context of domestic abuse, legislation criminalising coercive control is itself limited, as it would primarily only apply to ongoing intimate relationships (see e.g. Home Office 2015).

\section{"The Law Has Got to Catch Up": A Framework for a Comprehensive Criminal Law}

Participants in our study identified that the criminal law is, without doubt, failing victim-survivors of image-based sexual abuse. It is failing to protect people's sexual integrity and autonomy and it is failing to provide victim-survivors of image-based sexual abuse with justice and an adequate form of redress. In addition, the inadequacies and gaps in the law often make the experience worse by causing, or contributing to, additional harms such as widespread naming and shaming. Furthermore, the inconsistencies in the treatment of victim-survivors of image-based sexual abuse, depending on how the abuse was manifested, are unjustified and lead to unnecessary complexity and injustices. These distinctions between forms of abuse are even more problematic when a victim-survivor is forced to turn to multiple laws in respect of the same matrix of abuse.

As noted above, the majority of victim-survivors we spoke to in the UK (and across all three jurisdictions in our study) had experienced more than one form of image-based sexual abuse, most often having had images taken, threatened and shared without their consent (these findings are also supported by our survey results, see Henry et al. 2021). Thus, a criminal law which separates out these experiences,

13 Abusive Behaviour and Sexual Harm (Scotland) Act 2016, s 2. 
applying different thresholds, motivations and other requirements for the different elements of abuse, fails to recognise and understand the nature of these offences. The abuse is not experienced separately as 'distribution without consent' and 'voyeurism', or whatever particular criminal law category applies in that situation. Rather, victim-survivors experience image-based sexual abuse, sometimes multiple differing abuses, sometimes over time, but all connected and related, needing to be understood as a whole. As Liz Kelly has described in relation to sexual harassment and violence, and affirmed by our participants, victim-survivors' experiences "shade into and out of a given category" (Kelly 1988, 48) — meaning that it is vital to understand these abuses on a 'continuum'.

This is the rationale for the concept of 'image-based sexual abuse' which describes a range of interrelated forms of abuse and which draws on the conceptual insights of Liz Kelly and her idea of the 'continuum of sexual violence' (Kelly 1988; McGlynn and Rackley 2017; McGlynn et al. 2017). Kelly’s predominant concern was to provide the conceptual tools by which women's experiences of men's violence could be better understood, as they were (and still are) not reflected in the "legal codes or analytic categories" of existing research (Kelly 1988, 74; McGlynn et al. 2017, 27). Fundamentally, therefore, the continuing mis-categorisation of image-based sexual abuse, and the ad hoc and piecemeal categorisation of offences, fails to ensure legal remedies are grounded in victims' experiences and harms. For these reasons, what is needed is a conceptualisation and legal approach which embraces some breadth and flexibility, creating a "framework in which new experiences can be located and accurately understood as abusive-something which is especially important in this area where modes of perpetration rapidly change due to advances in technology" (McGlynn et al. 2017, 28).

Our research, therefore, supports the criticisms of the existing laws and the calls for reform that have been made by academics, stakeholders and victim-survivors alike (see e.g. Gillespie 2015; McGlynn and Rackley 2017; North Yorkshire Police and Fire Commissioner 2018; Gallagher 2019; Gillespie 2019; Dymock and van der Westhuizen 2019). It is vital that the criminal law moves away from the current ad hoc and piecemeal approach which fetishises specific forms of image-based sexual abuse. Research across the UK, New Zealand and Australia has found widespread community support for the criminalisation of image-based sexual abuse, with more than four in five respondents supporting legislation (Henry et al. 2021). What is needed is a comprehensive law criminalising all forms of image-based sexual abuse, including threats and altered or fake images, and which focuses on the absence of consent, rather than the perpetrator's motives, the location of the conduct, or the form of the images. 


\section{Reclaiming Control: A Multi-stranded Approach to Justice for Victim-Survivors of Image-Based Sexual Abuse}

While many of the victim-survivors had engaged (with varying degrees of success) with the criminal justice process, it is clear that few saw this as the only-or indeed best-avenue for support and redress. Rather, what is clear from their responses is a desire to 'reclaim control' of their images, bodies, lives, relationships, careers, and physical and mental health. For many, this-rather than punishment of the perpetrator of the abuse - was their primary concern. What is required, therefore, is an approach which provides a multi-stranded, multi-institutional and multi-agency response that allows victim-survivors to simultaneously or consecutively pursue one or more of a number of options within and beyond the criminal justice system. In this final section, we discuss four avenues identified by the UK victim-survivors and stakeholders we spoke to, through which victim-survivors of image-based sexual abuse might seek justice and reclaim control. We then make a case for the establishment of an Office for Online Safety in the UK charged with putting this approach into practice, much like that currently operating in Australia (Henry et al. 2019a, b).

\section{Recognition, Education and Restorative Approaches}

\section{"I wish that someone had sat him down and said 'this is wrong"'}

As with other survivors of sexual violence, what constitutes 'justice' for victim-survivors of image-based sexual abuse is, to use McGlynn and Westmarland's term, 'kaleidoscopic'. Justice is neither fixed nor linear, but rather a "continually shifting pattern ... constantly refracted through new circumstances, experiences and understandings ... [with] multiple beginnings and possible endings" (McGlynn and Westmarland 2019, 186). There are, in other words, many different ways of enabling a sense of justice, from securing consequences for the perpetrator, developing educational and prevention responses, and treating victim-survivors with dignity and affording them recognition of the harms experienced. While almost all of the UK victim-survivors we spoke to (and indeed across the larger study) referred to the criminal justice system when considering what justice looked like, it was equally evident that for most, this was just one route among many to securing justice, and for some, not an option at all. For example, Kimberly, whose ex-boyfriend took naked photos of her without her consent while she was sleeping, was wary of engaging with the criminal justice system due to its potential long-term consequences:

[The criminal justice system] was never really on my radar. ... Because ... he was, what, 20 at the time. And I thought I don't really know what could happen but I just thought he's very young and actually the person who he is when he's 40 or 50 years old is probably not going to be that same person, and is it worth ruining so much for him? 
Overall, what emerged was a complex and varying picture, at the heart of which was a desire to ensure greater recognition of the wrongfulness of the abuse and the harms of their experiences; often a desire for "some kind of punishment, but not prison," possibly through more 'restorative' approaches which were seen by some to be more effective (in terms of attitudinal change) than a prison sentence.

Thus, some victim-survivors spoke of wanting to convey to the perpetrator and others the full impact and harms of what had happened to them, often (but not always) with the hope that the perpetrator would take responsibility for what they had done. Mary, who had had images taken and posted on a WhatsApp group chat without her consent, commented: "I think, looking back now, an apology would have been nice, or some ownership of, 'Okay, I thought you would have been okay with that and I'm sorry, I should have asked."' This comment is indicative of others. A number of the victim-survivors had contacted the perpetrator directly. For Kimberly this had helped her to obtain 'closure':

Maybe two years, three years [later], I sent him ... [a] WhatsApp message basically saying "I know what you did. I want you to know that this is very wrong. ... This is the impact it's had on me since. ... I hope you haven't done it to anyone else. Don't do it to anyone else in the future." And then ... [I said] "I have genuinely forgiven you." And it actually was such a release for me to be able to say that as well, which felt really good. ... Within about five minutes, probably less than that, he'd sent me a response [in which he admitted it was wrong].

While any such encounters must be approached with great caution, and will be more or less appropriate depending on the circumstances of the abuse, it is clear that some victim-survivors would find a form of facilitated engagement a helpful option. Echoing the experiences of other sexual violence survivors (McGlynn et al. 2012), and a sentiment similar to Kimberly, Danielle expressed her wish to:

Confront [the perpetrator] about it and just tell him what he'd done and like how awful it made me feel, and just make it clear to him like what he did was wrong and why it was wrong and what the consequences were of it.

\section{"It isn't normal ... and it's not okay to do"}

Understandably, many of those we spoke to did not want to- or could not—speak to the perpetrator directly, with others seeking a response which extended beyond the individual perpetrator. In these and other cases, the police we spoke to had also engaged in a variety of informal responses. For approximately half of the cases where victim-survivors had reported their abuse to the police, the police resorted to using informal methods of direct action, for example, by issuing requests that images be taken down or destroyed, or informing the perpetrator that their ongoing behaviour could amount to a criminal offence. Such responses commonly took place in situations where the abuse fell outside the current criminal law, or where they felt 
there was not enough evidence to prosecute. Sarah, whose ex-boyfriend had posted 'fake' pornographic pictures of her on a mainstream porn website, told us:

So the police officer and I agreed that I would get hold of [the perpetrator's] mobile number and the officer would call him and give him an informal caution and tell him to take [the sexual images] down immediately or they would come down and go through all his computers with a fine-toothed comb. ... I think the threat ... was a complete bluff, but it did seem to do the trick ... they [were taken] down within about 20 minutes of that phone call being made.

Some victim-survivors felt that these informal responses allowed the perpetratorsin the words of Frances-to "get off scot free," or were simply another way in which the police minimised the seriousness of the abuse. Nonetheless, in some cases, they offered (at least partially) some form of resolution. This was particularly in relation to threats, where an informal warning of the likely legal consequences of the threat being carried out, on some occasions, appeared to be enough to prevent the images from being disseminated and the occurrence of future threats. While these informal responses raise many questions, including the motivations and constraints of the police (see also McGlynn et al. 2018), they at least identify avenues where proactive policing could have an effect.

Other participants talked of the need for a 'cultural change', identifying the need for widespread and bespoke education on the impact and effects of image-based sexual abuse. Echoing the views of many, Heather commented:

They're sharing it because they think it's a cool thing to do and [do] not realise the effect that it actually has on the person, and I think if they were more aware [that might change] ... even if it was just one of them that changed their view.

This highlights not only victim-survivors' desire for education, as a form of justice, but also emphasises the fallacy of the criminal law in assuming perpetrators are motivated purely by malice. Victim-survivors are telling us their apparent motives are wider than this, and therefore educational responses must also be broader. Further, in view of research finding little awareness of current criminal laws against image-based sexual abuse (Henry et al. 2021), there is also a need for comprehensive education and awareness-raising on the nature of the criminal law.

\section{Utilising the Civil Law}

The criminal law is, of course, not the only option for redress, with the civil law offering another avenue through which victim-survivors may be able to reclaim control. While some jurisdictions have introduced bespoke civil remedies (see e.g. the Crimes Amendment (Intimate Images) Act 2017 in New South Wales, Australia), this is not the case in the UK. What this means is that while civil law options can be effective, they are often underused and expensive. The victim-survivors we spoke to were either unaware of civil law remedies, or had dismissed them because, in the 
words of one stakeholder working with victim-survivors, they are "not economically viable for most of the human race".

This is a considerable injustice, because civil claims for image-based sexual abuse are, in the words of one lawyer we spoke to, "nearly all slam-dunk cases". Certainly, there is a veritable smorgasbord of civil law options-including harassment, privacy, data protection, defamation and the pre-emptive use of injunctions and non-disclosure orders-and a growing case law in the UK putting posters, forwarders and hosters of image-based sexual abuse on notice: the civil law has teeth and - if it bites — can leave perpetrators, and (in some cases) those who enable them, liable for substantial damages (Horsey and Rackley 2018; Brown 2018).

Unlike the criminal law, civil law puts the victim-survivor-at least for those who can afford it-back in control (Godden-Rasul 2015; McGlynn and Rackley 2017). As one lawyer told us:

When you bring a civil action, you retain control over the position; whereas, if you deliver something to the police, you don't have to gather evidence, which is great, but essentially the issue is taken out of your hands and it is processed by the police and given to the CPS [Crown Prosecution Service], and they can decide what to do.

In the context of image-based sexual abuse, where one of the ongoing harms is the inability to control who sees your image, and how or when they do so, this power is particularly important. The civil law also offers more opportunity for recognition. Another lawyer we spoke to explained:

At the end of the case ... you can have a moment ... during which you can have an open statement read in court. And the importance of this is that you are publicly vindicated as the claimant ... and because it's an open statement it can be publicised, ... anyone can listen to it. ... [In] that statement the defendant will acknowledge what they've done, they will retract it or apologise for it [and it will state] the outcome of the case, like "it was settled for substantial damages". ... And I think that's extremely important for claimants. ... I think it does really empower victims.

The sticking point, of course, is money. Many perpetrators may well be, in effect, "judgment-proof", having neither the means nor the inclination to respond appropriately to a judgment against them (Citron and Franks 2014, 358). Despite ongoing efforts by law firms to reduce the costs of initial consultations, including the possibility of 'no win, no fee' arrangements, the cost of raising a civil claim often means that access to this form of redress is dependent on the availability of substantial resources and an ability to access legal advice and is therefore distributed unequally, for example, excluding certain socio-economic groups from redress. Access to civil legal aid is limited (unless the image-based sexual abuse takes place within the context of domestic abuse) and non-existent for individuals with 
no recourse to public funds; and, even with such funding, bringing a civil suit can still be a huge undertaking.

That said, while perpetrators of image-based sexual abuse may not be worth pursuing, websites and others hosting the images may well be. Many victim-survivors spoke of their desire to hold the online platforms accountable-and for them to take responsibility-for the perpetuation and constancy of the harms they were experiencing (O'Connell 2020). Though most digital platforms and services, including social media and search engine companies, have processes to remove images, these are often slow, complicated, and sometimes reliant on personal connections with organisations. Lucy, whose ex-boyfriend had uploaded images onto porn websites without her consent, reflected a common view when she said that it feels as if the sites "can just wash their hands of it":

For me it would be a way of ensuring that the websites themselves aren't able to publish these pictures, or that they're shut down. ... I'm not particularly vengeful, ... so I wouldn't even be that bothered about seeing my ex behind bars or anything like that. I would just prefer to be able to move forward and live my life normally. But I don't feel that I can do that if these pictures are constantly popping up, and people are sharing them.

This is extremely worrying in light of our survey results finding that of those who have had sexual images shared without their consent, more than half $(55 \%)$ of victim-survivors discovered their images had been uploaded online; for almost a quarter $(23 \%)$ this included onto pornographic websites (and indeed many more may be unaware that this had happened) (Henry et al. 2021). A number of the victim-survivors with whom we spoke talked about "bringing claims against websites" who are making money from their abuse, and there was a strong sense, particularly among the lawyers we spoke to, that this is the next frontier in the fight against image-based sexual abuse. As one lawyer told us:

Our "legal crusade", for want of a better word, is really to try and create precedent that will hold websites to account for [hosting] these images. ... The problem there that we face is pinning down a website, finding its jurisdictional locus as it were. Because they are often, particularly the websites, ... owned through this extremely labyrinthine structure of offshore companies and shell companies and affiliate companies and subsidiaries. And it's very difficult to trace back who owns the actual website that's posted the image.

What this means is that at present such claims are time, technologically and financially expensive - they can require a heady mix of cross-jurisdictional lawyers and technological expertise (see also Henry et al. 2018a). And, of course, websites are likely to be 'extremely aggressive' in defending claims and resisting regulation. One lawyer stated: "I'm sure they would get out all their lobbying big guns to try and resist this as much as they possibly could." However, should 
this avenue prove to be successful, the technological landscape would change dramatically_images would disappear far more quickly, or not be posted at all and/ or victim-survivors would be eligible for significant financial compensation. ${ }^{14}$

\section{Practical, Technological and Emotional Support}

Without exception, the key priority for victim-survivors in whatever jurisdiction is the removal or take-down of their images from wherever they have been posted. The first port of call for many was the police, often believing them to have more power and/or influence than they did (see also Henry, Flynn and Powell 2018a). In fact, the vast majority of police have very limited expertise or resources in this area. While in the UK organisations and peer communities like the Revenge Porn Helpline and Victims of Internet Crime (VOIC) provide excellent technical and practical support, they do so either unfunded or underfunded and have limited capacity. As one stakeholder who works with victim-survivors told us:

We've had cases where things have ... been online for years. ... You do get that slight sinking feeling when you search one image ... and they say "I've found it on three websites", and you do a reverse image search ... and you find it on 10 pages ... of Google search results. And then you go, "Ok, this is going to take a while to go through".

As a result, victim-survivors can often conduct their investigations alone, or with the help of trusted friends. But this is not without significant consequences. As another stakeholder who works with victim-survivors put it, "they have to look for their own abuse online, to find it, in order to report it" and this constant viewing of the images can itself be significantly traumatising.

Due to the significant harms of image-based sexual abuse, victim-survivors also need access to specific emotional and psychological support to help them deal with their experiences. The limited understanding of the constancy and enduring nature of the harms of image-based sexual abuse means that securing appropriate counselling and support has proven challenging for our participants. Further, as with other forms of sexual abuse, accessing such services is often difficult due to limited resources which cause long waiting lists. In Anna's words:

The support system for people who have had this happen to them, it needs to be more available to people, because if you're waiting on the NHS to give you help with anything, any therapy or anything like that, you'll be off the bloody bridge and you'll be gone by the time they phone.

\footnotetext{
14 The UK Government is considering further regulation of websites including a 'statutory duty of care' to protect users from harm (DCMS 2020).
} 
In the UK, cuts and underfunding have significantly restricted the availability of specialist support services in particular, including specialist services for black and minoritised women (see e.g. NCVO 2019; Thiara and Roy 2020). This is despite these services providing crucial support and expertise that address the intersectional risks and harms that may be engendered by image-based sexual abuse. Stakeholders who work with black and minoritised women, for example, highlighted the additional risks, institutional discrimination, barriers and impacts that such women often face, due to interlocking structural inequalities and oppressions such as racism, xenophobia, migrant status and the related 'hostile environment', misogyny and so-called honour-based violence. It is vital that efforts to improve the provision of emotional, psychological and practical support for victim-survivors ensure that there is a range of well-resourced services equipped to support all victim-survivors, across BAME, LGBTQI+ and disability sectors.

\section{Conclusions: An Embedded, Co-ordinated and Resourced Response to Image-Based Sexual Abuse}

Image-based sexual abuse is a pernicious and multifaceted form of abuse. Its presence and impact spans multiple jurisdictions. A multi-dimensional response is needed in order to provide some measure of justice and redress for victim-survivors. This requires targeted investment and political leadership. The current ad hoc situation is not only failing victim-survivors of image-based sexual abuse, but is making their experiences worse. This article has sought to provide an evidence base, detailing victim-survivors' experiences and perspectives on what justice and redress means to them. It also provides clear evidence that action is urgently required to provide redress and reduce further victimisation.

Reforming the criminal law, while necessary, is not enough. What is also needed is a coherent strategy that combines proactive and reactive practical, legal and emotional support led by a public body accountable to Parliament for the implementation of this strategy. To this end, we recommend the establishment of an 'Office for Online Safety', a national, Government and/or industry-funded body. ${ }^{15}$ This follows the approach of similar organisations in Australia (the eSafety Commissioner), New Zealand (Netsafe) and South Korea's Advocacy Centre for Online Sexual Abuse Victims, as well as that proposed by the Irish Law Reform Commission (Law Reform Commission 2016, [4.18]). The Office would provide a central and authoritative hub of well-resourced and expert technological and legal assistance, and adopt a proactive educative role in combating image-based sexual abuse. Drawing on the best practice of the Internet Watch Foundation (charged with eliminating child

\footnotetext{
15 Such an organisation may form part of the Government's broader regulatory mechanisms dealing with online harms (such as those proposed in DCMS/HD 2019). But, so far, these do not include direct help and support for victim-survivors, and the educative focus is on individuals protecting themselves, rather than challenging abusive and misogynistic attitudes and behaviours (End Violence Against Women 2019).
} 
sexual abuse imagery online) and others, the Office would be positioned to provide international guidance and support, building the cross-jurisdictional relationships needed in order to provide practical assistance to victim-survivors to regain control of their images. It would oversee the resourcing of specialist support services for victim-survivors, including counselling and legal advocacy through organisations such as the Revenge Porn Helpline and VOIC. It would also fulfil a duty to resource and champion educational initiatives to challenge cultural attitudes and behaviours that sustain online and image-based sexual abuse.

Now is not the time for tinkering around the edges of current law and support. It is time to listen to victim-survivors of image-based sexual abuse, taking their experiences and perspectives as the foundation from which to build a co-ordinated strategy. It is time for political leadership and targeted resources. It is time for fundamental change.

Acknowledgements We are enormously grateful to the many victim-survivors who generously gave their time to talk with us about their experiences: you are all a continued source of motivation and inspiration. We also wish to acknowledge and thank the stakeholders and practitioners who were so generous with their time and expertise. We are grateful for the insights, comments and wisdom of the journal's anonymous referees and editorial board and of Adrian Scott, our partner investigator. We are also hugely grateful to Magdalena Furgalska, Jessamy Gleeson and Sarah McCook for their excellent research assistance. The research was funded by an Australian Research Council Discovery project grant (DP170101433). Erika Rackley also gratefully acknowledges the support of the Philip Leverhulme Trust (PLP-2014-193).

Open Access This article is licensed under a Creative Commons Attribution 4.0 International License, which permits use, sharing, adaptation, distribution and reproduction in any medium or format, as long as you give appropriate credit to the original author(s) and the source, provide a link to the Creative Commons licence, and indicate if changes were made. The images or other third party material in this article are included in the article's Creative Commons licence, unless indicated otherwise in a credit line to the material. If material is not included in the article's Creative Commons licence and your intended use is not permitted by statutory regulation or exceeds the permitted use, you will need to obtain permission directly from the copyright holder. To view a copy of this licence, visit http://creativecommons.org/licen ses/by/4.0/.

\section{References}

Ajder, Henry, Giogio Patrini, Francesco Cavalli, and Laurence Cullen. 2019. The State of Deepfakes: Landscape, Threats, and Impacts. Amsterdam: Deeptrace.

Bates, Samantha. 2017. Revenge porn and mental health: A qualitative analysis of the mental health effects of revenge porn on female survivors. Feminist Criminology 12: 22-42.

Bradley, Karen. 2016. Letter to Alistair Carmichael MP from Karen Bradley MP (then Minister for Preventing Abuse, Exploitation and Crime). 30 June. https://claremcglynn.files.wordpress.com/2016/ 07/gov-pcb-anon-ltr-to-libdems-30-june-2016.pdf. Accessed 27 September 2019.

Bond, Emma, and Katie Tyrell. 2018. Understanding revenge pornography: A national survey of police officers and staff in England and Wales. Journal of Interpersonal Violence 36: 1-16.

Brown, Jonathan. 2018. Revenge porn' and the actio iniuriarum: Using 'old law' to solve 'new problems. Legal Studies 38 (3): 396-410.

Citron, Danielle Keats, and Mary Anne Franks. 2014. Criminalizing revenge porn. Wake Forest Law Review 49: 345-391.

Chalmers, James, and Fiona Leverick. 2017. The Criminal Law of Scotland, Vol 2, 4th ed. Edinburgh: Green. 
Chesney, Bobby, and Danielle Keats Citron. 2019. Deep Fakes: A looming challenge for privacy, democracy and national security. California Law Review 107: 1753-1819.

Childnet International. 2019. Online Sexual Harassment: Understand, Prevent and Respond-Guidance for Schools on Addressing Online Sexual Harassment. https://www.childnet.com/ufiles/Guidance for_Schools_Online_Sexual_Harassment.pdf. Accessed 7 January 2020.

Crenshaw, Kimberle. 1991. Mapping the margins: Intersectionality, identity politics and violence against women of colour. Stanford Law Review 43 (6): 1241-1299.

Digital, Culture, Media \& Sport and Home Department (DCMS/HD). 2019. Online Harms White Paper (April). https://assets.publishing.service.gov.uk/government/uploads/system/uploads/attachment_ data/file/793360/Online_Harms_White_Paper.pdf. Accessed 8 January 2020.

Dodge, Alexa. 2020. Trading nudges like hockey cards: Exploring the diversity of 'revenge porn'cases responded to in law. Social and Legal Studies. Online first.

Dymock, Alex, and Charlotte van der Westhuizen. 2019. 'A dish served cold: Targeting revenge in revenge pornography. Legal Studies 39 (3): 361-377.

End Violence Against Women. 2019. Submission to Government consultation on the online harms white paper. https://www.endviolenceagainstwomen.org.uk/evaws-response-to-the-online-harms-consultati on/. Accessed 10 March 2020.

Flynn, Asher. 2019. Image-Based Abuse: The Disturbing Phenomenon of the 'Deep Fake'. Monash Lens, 12 March. https://lens.monash.edu/@politics-society/2019/03/12/1373665/image-based-abuse-deep-fake. Accessed 13 April 2021.

Flynn, Asher and Nicola Henry. 2019. Image-based sexual abuse: An Australian reflection. Women and Criminal Justice. Online first.

Gallagher, Sophie. 2019. Why revenge porn needs to be in the Domestic Abuse Bill: 'The images were used to destroy my life'. Huffington Post, 5 September. https://www.huffingtonpost.co.uk/entry/why-revengeporn-needs-to-be-in-the-domestic-abuse-bill-the-images-were-used-to-destroy-my-life_uk_5d6e19e7e4 b09bbc9ef3dde8v. Accessed 13 April 2021.

Gavey, Nicola, and Johanna Schmidt. 2011. "Trauma of rape" discourse: A double-edged template for everyday understandings of the impact of rape? Violence Against Women 17 (4): 433-56. https://doi. org/10.1177/1077801211404194.

Gillespie, Alisdair. 2015. 'Trust me, it's only for me': Revenge porn and the criminal law. Criminal Law Review 11: 866.

Gillespie, Alisdair. 2019. 'Tackling voyeurism: Is the Voyeurism (Offences) Act 2019 a wasted opportunity? Modern Law Review 82 (6): 1107.

Godden-Rasul, Nicola. 2015. Retribution, Redress, and the Harms of Rape: The Role of Tort Law. In Rape Justice: Beyond the Realm of Law, ed. Anastasia Powell, Nicola Henry, and Asher Flynn, 112-126. Basingstoke: Palgrave Macmillan.

Hall, Matthew, and Jeff Hearn. 2017. Revenge pornography and manhood acts: A discourse analysis of perpetrators' accounts. Journal of Gender Studies 28 (2): 158-170.

Harding, Sandra G. (ed.). 2004. The feminist standpoint theory reader: Intellectual and political controversies. New York; London: Routledge.

Haynes, Jason. 2018. Legislative approaches to combating 'revenge porn': A Multijurisdictional Perspective. Statute Law Review 39 (3): 319-336.

Henry, Nicola, Asher Flynn, and Anastasia Powell. 2018a. Policing image-based sexual abuse: Stakeholder perspectives. Police Practice and Research: An International Journal 19 (6): 565-581.

Henry, Nicola, Asher Flynn, and Anastasia Powell. 2019. Responding to revenge pornography: The scope, nature and impact of Australian criminal laws: A report to the criminology research council. Canberra: Australian Institute of Criminology.

Henry, Nicola, Anastasia Powell and Asher Flynn. 2017. Not just 'revenge pornography': Australians' experiences of image-based abuse: A summary report. https://www.rmit.edu.au/content/dam/rmit/docum ents/college-of-design-and-social-context/schools/global-urban-and-social-studies/revenge_porn_ report_2017.pdf. Accessed 8 January 2020.

Henry, Nicola, Anastasia Powell and Asher Flynn. 2018b. AI can now create fake porn, making revenge porn even more complicated. The Conversation, 1 March. https://theconversation.com/ai-can-now-createfake-porn-making-revenge-porn-even-more-complicated-92267. Accessed 13 April 2021.

Henry, Nicola, Clare McGlynn, Asher Flynn, Kelly Johnson, Anastasia Powell, and Adrian Scott. 2021. Image-Based Sexual Abuse: A Study on the Causes and Consequences of Non-Consensual Nude or Sexual Imagery. Abingdon: Routledge.

Hill Collins, Patricia, and Sirma Billge. 2016. Intersectionality. Cambridge: Polity Press. 
Holmes, Zeb. 2019. 97\% of new deepfakes are pornographic, experts believe revenge porn will spike. The Big Smoke, 21 November. https://www.thebigsmoke.com.au/2019/11/21/97-of-new-deepfakes-arepornographic-experts-believe-revenge-porn-will-spike/.. Accessed 8 January 2020.

Home Office. 2015. Controlling or coercive behaviour in an intimate or family relationship: statutory guidance framework. https://www.gov.uk/government/publications/statutory-guidance-framework-contr olling-or-coercive-behaviour-in-an-intimate-or-family-relationship. Accessed 13 April 2021.

Horsey, Kirsty, and Erika Rackley. 2018. Tort Law. In Great Debates in Gender and Law, ed. Rosemary Auchmuty, 13-24. London: Palgrave Macmillan.

Kelly, Liz. 1988. Surviving Sexual Violence. Cambridge: Polity Press.

Law Reform Commission. 2016. Harmful communications and digital safety (LRC 116-2016). https://www. lawreform.ie/_fileupload/Reports/Full\%20Colour\%20Cover\%20Report\%20on\%20Harmful\%20Com munications\%20and\%20Digital\%20Safety.pdf. Accessed 13 April 2013.

Lyons, Izzy. 2019. Revenge porn threats should be made illegal, review suggests, after Alice Ruggles murder. Daily Telegraph, 19 March. https:/www.telegraph.co.uk/news/2019/03/19/revenge-porn-threatsshould-made-illegal-review-suggests-alice/. Accessed 25 November 2019.

McGlynn, Clare. 2017. Revenge porn is a form of sexual assault. Huffington Post, 19 March. https://www. huffingtonpost.co.uk/clare-mcglynn/revenge-porn_b_15441782.html. Accessed 13 April 2021.

McGlynn, Clare. 2018. 'Revenge porn' and upskirting remind us sexual offending is not about sexual arousal. Huffington Post, 11 July. https://www.huffingtonpost.co.uk/entry/revenge-porn-and-why-sexual-offen ding-is-not-about_uk_5b45c9e7e4b00db1492ffe9f. Accessed 13 April 2021.

McGlynn, Clare, and Erika Rackley. 2017. Image-based sexual abuse. Oxford Journal of Legal Studies 37 (3): 534-561.

McGlynn, Clare, and Kelly Johnson. 2021. Cyberflashing: Recognising Harms, Reforming Laws. Bristol: Bristol University Press.

McGlynn, Clare, Kelly Johnson, Erika Rackley, Nicola Henry, Nicola Gavey, Asher Flynn and Anastasia Powell. 2020. 'It's torture for the soul': The harms of image-based sexual abuse. Social and Legal Studies. Online first.

McGlynn, Clare, Erika Rackley, Kelly Johnson, Nicola Henry, Asher Flynn, Anastasia Powell, Nicola Gavey, Adrian Scott. 2019. Shattering Lives and Myths: A Report on Image-Based Sexual Abuse. http://dro.dur. ac.uk/28683/3/28683.pdf?DDD34+DDD19+. Accessed 13 April 2021.

McGlynn, Clare, Erika Rackley, and Ruth Houghton. 2017. Beyond 'revenge porn': The continuum of image-based sexual abuse. Feminist Legal Studies 25 (3): 25-46.

McGlynn, Clare, Nicole Westmarland, and Nikki Godden. 2012. 'I just wanted him to hear me': Sexual violence and the possibilities of restorative justice. Journal of Law and Society 39 (2): 213-240.

McGlynn, Clare, and Nicole Westmarland. 2019. Kaleidoscopic justice: Sexual violence and victim-survivors' perceptions of justice. Social and Legal Studies 28 (2): 179-201.

McGlynn, Clare, Nicole Westmarland, and Kelly Johnson. 2018. Under the radar: The widespread use of "out of court resolutions" in policing domestic violence and abuse in the United Kingdom. British Journal of Criminology 58 (1): 1-16.

Mortreux, Colette, Karen Kellard, Nicola Henry and Asher Flynn. 2019. Understanding the attitudes and motivations of adults who engage in image-based abuse. Australia: Office of the eSafety Commissioner). https://www.esafety.gov.au/sites/default/files/2019-10/Research_Report_IBA_Perp_Motiv ations.pdf. Accessed 13 April 2021.

NCVO. 2019. UK Civil Society Almanc 2019. https://data.front-controller.ncvo.org.uk. 8 January 2020.

Nigam, Shradha. 2018. Revenge porn laws across the world. The Centre for Internet and Society, 25 April. https://cis-india.org/internet-governance/blog/revenge-porn-laws-across-the-world. Accessed 27 September 2019.

North Yorkshire Police, Fire \& Crime Commissioner. 2018. Suffering in silence: image-based sexual abuse report 2018. http://www.nomorenaming.co.uk/wp-content/uploads/2018/11/Suffering-in-Silence-2018. pdf. Accessed 27 September 2019.

O'Connell, Aislinn. 2020. Image rights and image wrongs: Image-based sexual abuse and online takedown. Journal of Intellectual Property Law and Practice. 15 (1): 55-65.

Powell, Anastasia, Nicola Henry, Asher Flynn, and AdrianJ.. Scott. 2019. Image-based sexual abuse: The extent, nature, and predictors of perpetration in a community sample of Australian residents. Computers in Human Behavior 92: 393-402.

Powell, Anastasia, Nicola Henry, and Asher Flynn. 2018. Image-based sexual abuse. In Handbook of Critical Criminology, ed. Walter S. DeKeseredy and Molly Dragiewicz, 305-315. London: Routledge.

Powell, Anantasia, and Nicola Henry. 2017. Sexual Violence in a Digital Age. Palgrave Macmillan. 
Rackley, Erika and Clare McGlynn. 2018. 'Upskirting' and 'revenge porn': The need for a comprehensive law. The Conversation, 15 June. https://theconversation.com/upskirting-and-revenge-porn-theneed-for-a-comprehensive-law-98403. Accessed 13 April 2021.

Ruvalcaba, Yanet, and Asia Eaton. 2020. Nonconsensual pornography among US adults: A sexual scripts framework on victimisation, perpetration and health correlates for women and men. Psychology of Violence 10 (1): 68-78.

Stark, Evan. 2007. Coercive Control: The Entrapment of Women in Personal Life. New York: Oxford University Press.

Thiara, Ravi, and Sumanta Roy. 2020. Reclaiming Voice: Minoritised Women and Sexual Violence. London: Imkaan.

Waldron, Jeremy. 2010. Dignity and defamation: The visibility of hate. Harvard Law Review 123: 1596-1657.

Publisher's Note Springer Nature remains neutral with regard to jurisdictional claims in published maps and institutional affiliations.

\section{Authors and Affiliations}

\section{Erika Rackley ${ }^{1}$ - Clare McGlynn ${ }^{2}$. Kelly Johnson ${ }^{2}$ - Nicola Henry ${ }^{3}$. Nicola Gavey ${ }^{4}$. Asher Flynn ${ }^{5}$. Anastasia Powell ${ }^{3}$}

Clare McGlynn

clare.mcglynn@durham.ac.uk

Kelly Johnson

k.m.johnson@durham.ac.uk

Nicola Henry

nicola.henry@rmit.edu.au

Nicola Gavey

n.gavey@auckland.ac.nz

Asher Flynn

Asher.Flynn@monash.edu

Anastasia Powell

anastasia.powell@rmit.edu.au

1 University of Kent, Canterbury, UK

2 Durham University, Durham, UK

3 RMIT University, Melbourne, Australia

4 University of Auckland, Auckland, New Zealand

5 Monash University, Melbourne, Australia 